\title{
A Study of Measurement for Dangerous Prediction on Static Lording Test Using Piezoelectric Limit Sensors
}

\author{
Nobuhiro Shimoi ${ }^{1}$, Carlos Cuadr ${ }^{2}$ \\ ${ }^{1}$ Department of Machine Intelligence and Systems Engineering, Akita Prefectural University, Yurihonjo, Japan \\ ${ }^{2}$ Department of Architecture and Environment Systems, Akita Prefectural University, Yurihonjo, Japan
}

\section{Email address:}

shimoi@akita-pu.ac.jp (N. Shimoi), carlos@akita-pu.ac.jp (C. Cuadra)

\section{To cite this article:}

Nobuhiro Shimoi, Carlos Cuadr. A Study of Measurement for Dangerous Prediction on Static Lording Test Using Piezoelectric Limit Sensors. American Journal of Remote Sensing. Vol. 3, No. 3, 2015, pp. 43-48. doi: 10.11648/j.ajrs.20150303.12

\begin{abstract}
Applicability of a new piezoelectric limit sensor to detect premonitory failure during static loading testing is discussed in this paper. Brick masonry specimens were subjected to compression tests to evaluate their mechanical properties and to investigate proposed sensor response. These new sensors consist of a glass pipe containing piezoelectric film elements for the measurement of signals during static loading tests. The glass pipe can be installed directly in brick masonry specimens or inserted into the holder. For this research, a brass tube holder was made. This report discusses examinations for glass pipe alone and glass pipe with brass holder.
\end{abstract}

Keywords: Smart Sensor, Health Monitoring, Piezoelectric Sensor

\section{Introduction}

Brick walls of masonry structures are apt to be unstable because of major earthquakes or aging degradation. We propose a simple monitoring system using a piezoelectric limit sensor for simple quantitative evaluation of damage status and change of stress and strain in brick walls of masonry structures by vibration measurement [1][2]. Many unreinforced masonry buildings throughout the world have not been designed to resist loads caused by earthquake or by sudden gravitational loading. Therefore, a major earthquake might demolish most such buildings, causing numerous casualties and bringing about huge losses destroying greater parts of cities and villages [3]- [7].
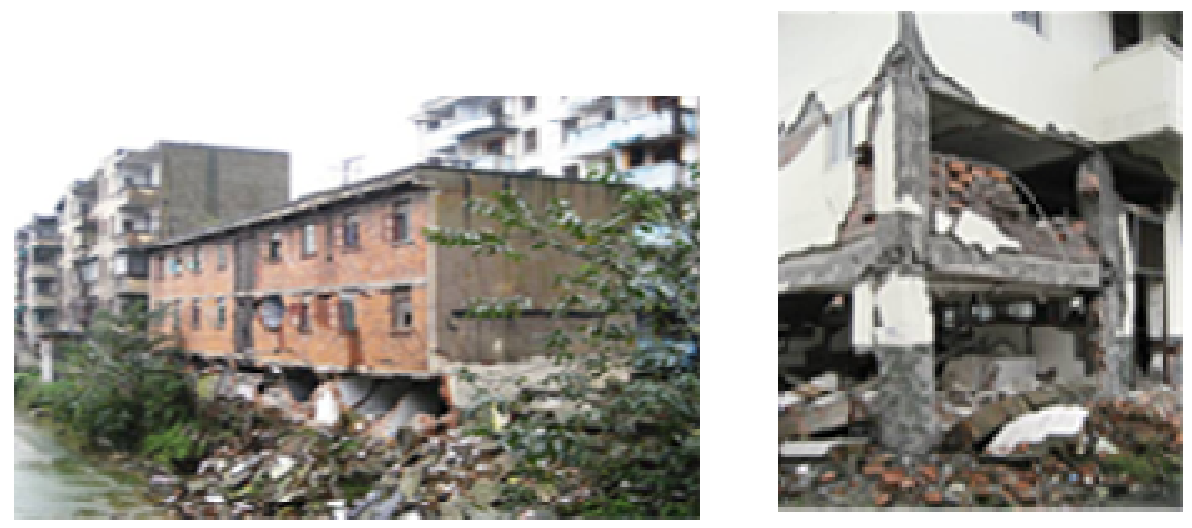

Fig. 1. Reinforcing the brick wall by earthquake effect $t^{6)}$.

Reinforcement of masonry buildings, including remodeling, is both important and necessary to avoid losses from catastrophic events. Nevertheless, in economically developing countries, few masonry structure specialists are available. Moreover, procuring proper materials for reinforcement is extremely difficult.[3]-[6] Figure 1 presents photographs of collapsed brick walls in Sichuan Province, China, taken immediately after a M7.9 earthquake occurred 
at 14:28, May 12, 2008, as reported by the US Geological

Survey (USGS) [7]. This report describes a simple sensor that is useful to monitor initial signs of destruction in structures and their dangerous state immediately before complete destruction, which are difficult to identify by vibration measurements with currently available measuring devices. The sensor was produced using simple and cheap sensors and PC technologies.

\section{New Measurement Technology for Brick Wall Specimen of Masonry Structures}

To prevent the problems explained above, reinforcement of the building of brick bond masonry structure, including the reconstruction, is extremely important. It might be done by compression testing in a vertical direction.

We conducted loading tests for a brick wall specimen of masonry structure, $210 \times 490 \times 420[\mathrm{~mm}]$, presented in Fig. 2 using a compression testing machine. We conducted compression measurements using a Pi-shaped displacement

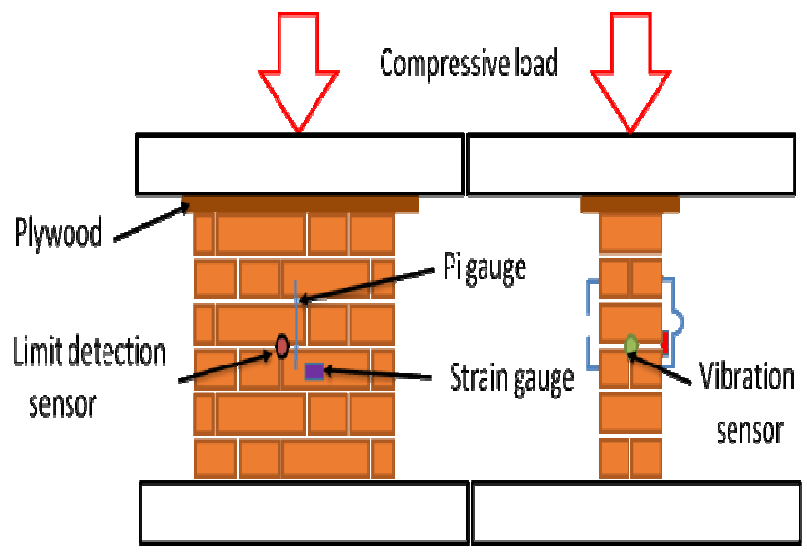

Fig. 2. Location of the sensor unit.

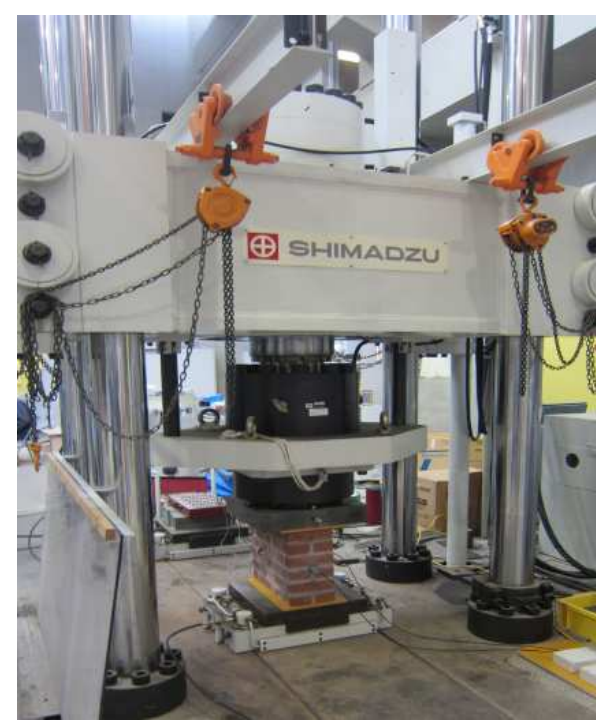

Fig. 3. Compression testing machine.
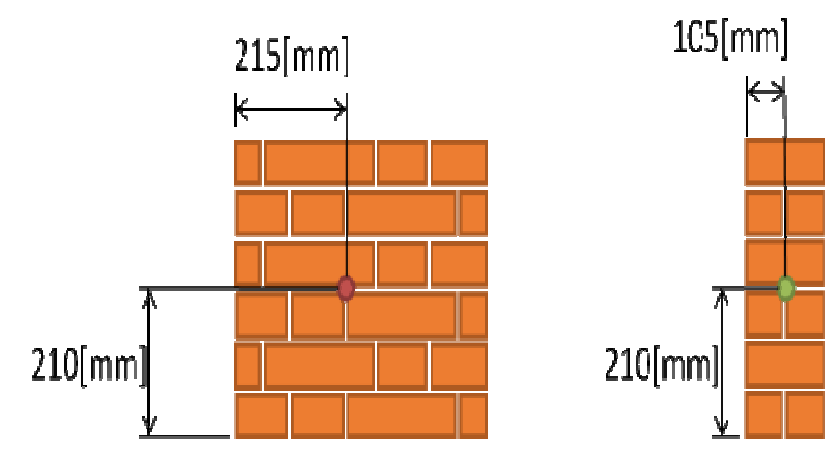

transducer (Pi gauge), taking distortion measurements using a distortion gauge, load measurements using a load cell, and deformation and vibration measurements using a piezoelectric limit sensor, simultaneously. Strain and compressive load were measured and mutually compared until specimens were completely destroyed. We examined the results of measurements by piezoelectric limit sensor (sensor for static load) to find if we were able to predict the state immediately before their complete destruction.

\section{Details of Sensors and Their Setup and Measuring Procedures}

In the brick wall of masonry structure, brick and mortar are applied one after another. This structure of missing homogeneity is weak in the bonding plane of different materials. Consequently, the weak strength at the bonding plane of brick and mortar makes the brick wall of masonry structure break at stress that is less than its member materials can withstand.

Table 1. Spec of compression testing machine.

\begin{tabular}{ll}
\hline Model & UH-5000kN- I \\
\hline Faculty max & $5000[\mathrm{kN}]$ \\
Load speed & $0 \sim 25[\mathrm{~mm} / \mathrm{min}](50 \mathrm{~Hz})$ \\
Stroke & $0 \sim 4000[\mathrm{~mm}]$ \\
\hline
\end{tabular}

Figure 3 portrays the compression testing machine (UH-5000kN I; Shimadzu Corp.) we used. Table 1 shows its specifications. We prepared two each of Flemish bond and English bond specimens for destruction testing. Then we set up sensors for specimens of these two types with different brick stacking patterns. We drilled $\phi 15$ holes in the front surfaces of these four specimens to insert sensors. Professional technicians stacked brick wall specimens for our quantitative measurements. Figure 4(1) presents details related to the piezoelectric limit sensor; Fig. 4(2) shows sensor setup patterns. When the sensor detects a load exceeding its limit by static loading, the piezoelectric film in the sensor deforms to generate a voltage. Because the sensor generates voltage proportional to deformation, we can 
estimate the scenario of destruction from its voltage output. The Pi gauge was fixed to the specimen by a bolt and a nut. The strain gauge was affixed to the specimen using adhesive and fixed to the specimen surface by mortar together with the piezoelectric limit sensor after it was inserted into the hole located in the center of the front surface. Sensors were wired to a high-performance memory logger (LR8431; Hioki E. E. Corp.) with a covered $\phi 4$-mm-diameter and 2-m-long lead wire. The cover of the wire provided proper electric insulation.
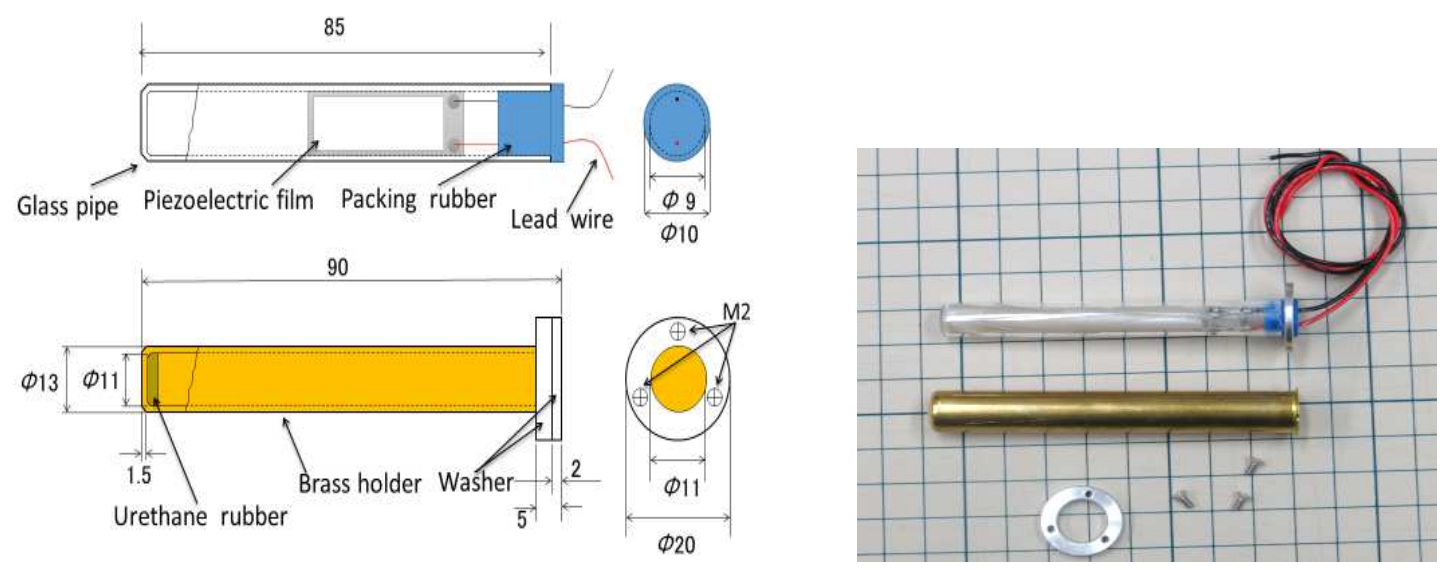

(1) Piezoelectric limit sensor.

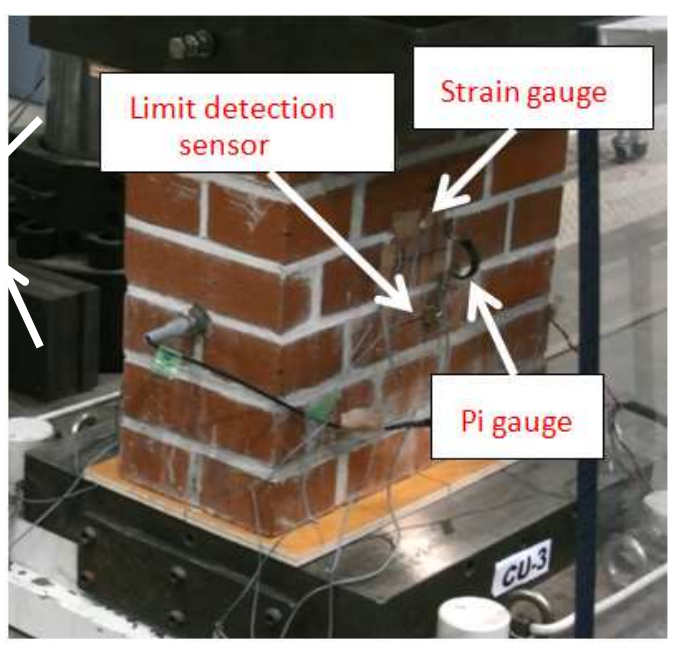

(2) Sensors and measurement setup.

Fig. 4. Experiment for sensors unit and test specimen.

\section{Destruction Testing of a Brick Wall Masonry Structure}

\subsection{Stress-Strain Relation}

We evaluated the strength of two bonds of brick. To find the difference of strength between Flemish and English bonds, we examined the relation between loading and average deformation in the specimen. As the average deformation, we used the arithmetic mean of two compressive deformations detected by two $\mathrm{Pi}$ gauges attached on front and rear surfaces of specimens. This value
The two Pi gauges (LR8431; Hioki E. E. Corp.) were fixed using a bolt (planted on the brick surface) and a nut on each front and rear surface of the specimen. Furthermore, we put a strain gauge (PFL-20-11-3L; Tokyo Sokki Kenkyujo Co. Ltd.) around center of front surface of specimen using adhesive and used it as an auxiliary sensor. Signals from these sensors were stored in the logger as time-series data. The sensor sampling frequency was $100 \mathrm{~Hz}$. That for gauges and compression loads was $1 \mathrm{~Hz}$. 
average strain in the specimen. Figure 5(1) is for Flemish bond specimen; Fig. 5(2) is for English bond specimen.

The average compression load and compressive stress at complete destruction in brick wall of masonry structure of the Flemish bond were about $3300[\mathrm{KN}]$ and about 32 $\left[\mathrm{N} / \mathrm{mm}^{2}\right]$, respectively. Although in the brick wall of the masonry structure of the English bond, they were about 3450 $[\mathrm{kN}]$ and about $33\left[\mathrm{~N} / \mathrm{mm}^{2}\right]$, respectively. For general evaluation of brick wall of masonry structure, people seem to expect better strength from the English bond than from the Flemish bond.[9] Our tests showed performance supporting that opinion. In design determination of safety load, people consider that about one-third of the destruction load might not cause any structural damage. These are calculated as shown below.

$$
\begin{gathered}
\mathrm{F}=\mathrm{A}_{\mathrm{s}} \times \sigma_{\mathrm{s}}=\mathrm{A}_{\mathrm{s}} \times \mathrm{E}_{\mathrm{s}} \times \varepsilon_{\mathrm{m}} \\
\sigma=\mathrm{F} \div \mathrm{A}_{\mathrm{s}}
\end{gathered}
$$

Therein, F stands for compressive load, As represents the sectional area of the compressed material, os signifies the average stress in the compressed material, Es denotes the Young's modulus (elastic coefficient) of the compressed material, and $\varepsilon m$ is the average strain. [10]

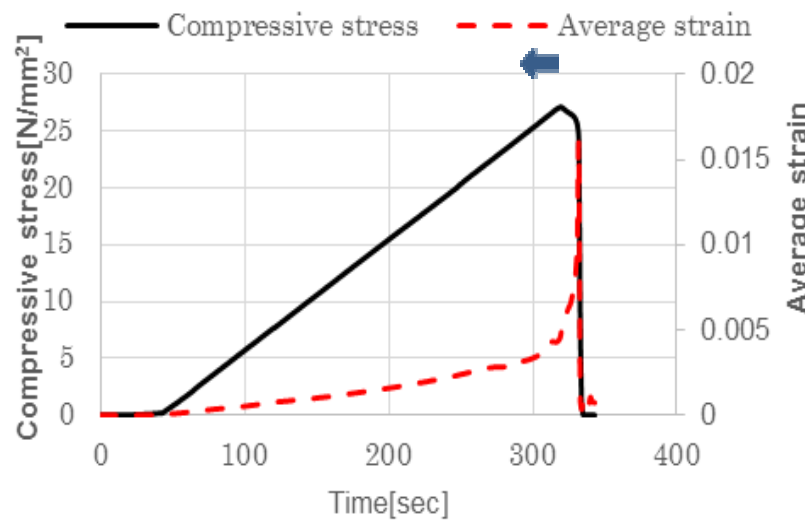

(1) Flemish bond specimen measurement for compressive stress and average strain

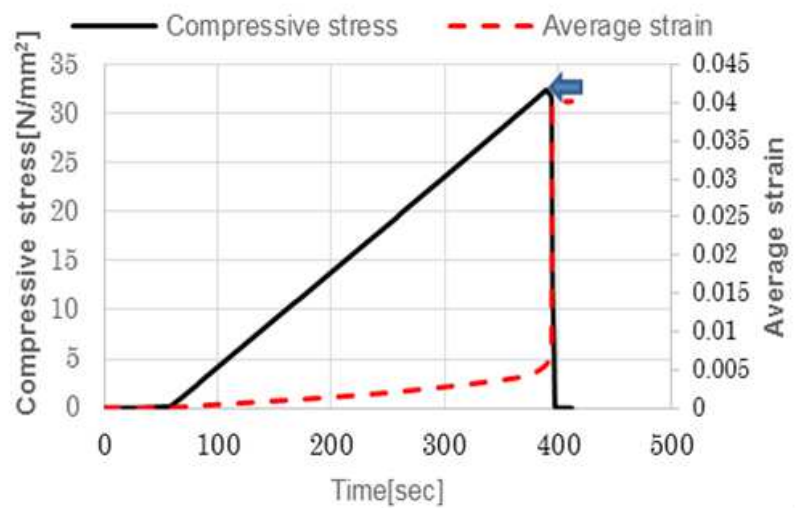

(2) English bond masonry specimen measurement for compressive stress and average strain

Fig. 5. Relation between compressive stress and average strain.
The average one-third loads of compressive destruction derived from Eqs. (4) and (5) were about 1,060 [kN] for the Flemish bond and about $1,168[\mathrm{kN}]$ for the English bond. In terms of stress, they were about $10\left[\mathrm{~N} / \mathrm{mm}^{2}\right]$ and about $11\left[\mathrm{~N} / \mathrm{mm}^{2}\right]$, respectively. It was estimated that destruction might start after this load and stress.

Although the maximum load and stress at destruction were about $3,105[\mathrm{kN}]$ and about $30\left[\mathrm{~N} / \mathrm{mm}^{2}\right]$, respectively, for the Flemish bond and about $3,429[\mathrm{kN}]$ and about $33\left[\mathrm{~N} / \mathrm{mm}^{2}\right]$ for the English bond. Therefore these experimental values compare well with the calculated ones presented above.

\subsection{Performance Evaluation of the Piezoelectric Limit Sensor}

Figure 6 shows the output of piezoelectric limit sensor and compressive stress. Figures 6(1) and (2) are for the Flemish bond and (3) and (4) for the English bond. We compared the calculated maximum compressive stress with the sensor output. We defined three symbolical quantities: (1) stands for compressive stress when destruction started, (2) when danger of destruction is predicted, and (3) when finally destroyed. The evaluation of experimental data on these items is described below.

Figure 6(1) shows the Flemish bond specimen and sensor in the brass holder. Results show that (1) occurred at ar-ound $130[\mathrm{~s}]$ and voltage of $0.008[\mathrm{~V}],(2)$ occurred at around 370 [s] and voltage of $0.016[\mathrm{~V}]$ and (3) occurred at around 400 [s] and voltage of $0.07[\mathrm{~V}]$. Rather large voltages recorded until around 120 [s] were noise caused by fluctuation of the oil pressure in the testing machine. Because we were unable to manage this irregularity, we simply disregarded the data during this time period and made no evaluation of them. Results show that (1) was $10\left[\mathrm{~N} / \mathrm{mm}^{2}\right],(2)$ was $31\left[\mathrm{~N} / \mathrm{mm}^{2}\right]$, and (3) was $33\left[\mathrm{~N} / \mathrm{mm}^{2}\right]$. On comparing these measured values, the allowable one-third of the maximum compressive stress was $11\left[\mathrm{~N} / \mathrm{mm}^{2}\right]$.

The maximum compressive stress was $33\left[\mathrm{~N} / \mathrm{mm}^{2}\right]$. Both compare well with each other. Our sensor measured stresses of (1) - (3). Results confirmed $31\left[\mathrm{~N} / \mathrm{mm}^{2}\right]$ as (2) with sensor output of 0.016 [V].Figure 6(2) shows the Flemish bond specimen and sensor in the glass holder: (1) was not detected; (2) occurred at around 320 [s] with sensor output of 0.018 [V]; and (3) happened at around 340 [s] with sensor output of 0.095 [V]. Actually, (1) was not measured, (2) was $26\left[\mathrm{~N} / \mathrm{mm}^{2}\right]$, and (3) was $28\left[\mathrm{~N} / \mathrm{mm}^{2}\right]$. On comparing these values with those obtained from Eqs. (1) and (2), we presumed that we measured $10\left[\mathrm{~N} / \mathrm{mm}^{2}\right]$ at $140[\mathrm{~s}]$ as output corresponding to (1). However, it did not appear. Because 28 $\left[\mathrm{N} / \mathrm{mm}^{2}\right]$ was recorded when the limit sensor indicated a maximum output, we confirmed that the measured value coincided well with the calculated one. Rather high sensor output at $<3>$ might have been caused by destruction of a specimen subjected to buckling deformation. Furthermore, the sensor supplied an advance signal of 0.016 [V] and stress of $26\left[\mathrm{~N} / \mathrm{mm}^{2}\right]$ corresponding to (2) at 295 [s]. That gives proper notice of final destruction. 


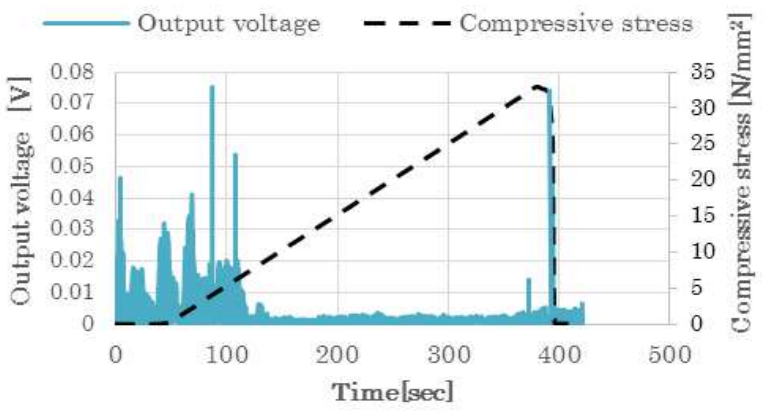

(1) Flemish bond specimen measurement by limit sensor with a brass holder for compressive stress and output voltage

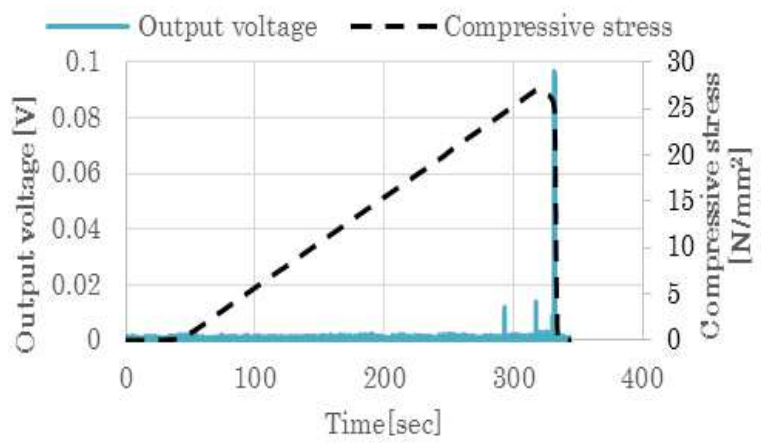

(2) Flemish bond specimen measurement by limit sensor with glass holder for compressive stress and output voltage

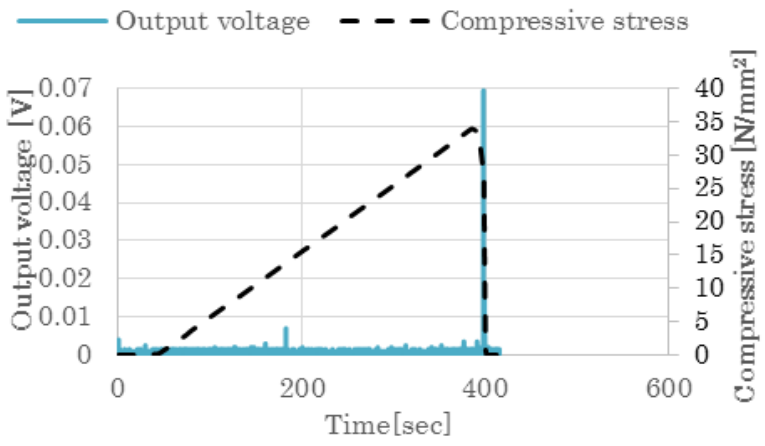

(3) English bond masonry specimen measurement by limit sensor with a brass holder for compressive stress and output voltage

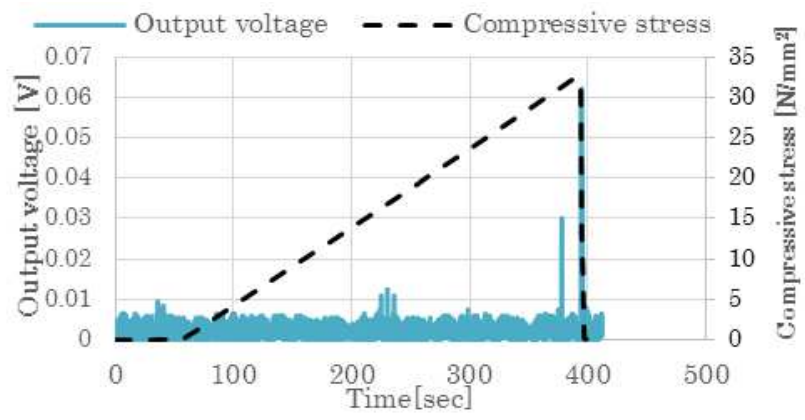

(4) English bond masonry specimen measurement by limit sensor with a glass holder for compressive stress and output

Fig. 6. Relation between the piezoelectric limit sensor output and compressive stress.
Figure 6(3) shows the English bond specimen and sensor in the brass holder. Results show that (1) occurred at around 180 [s] with voltage of 0.008 [V], (2) at around 380 [s] with voltage of $0.038[\mathrm{~V}]$, and (3) at around 400 [s] with voltage of 0.07 [V]. Also, (1) was $13\left[\mathrm{~N} / \mathrm{mm}^{2}\right]$, (2) was $33\left[\mathrm{~N} / \mathrm{mm}^{2}\right]$, and (3) was $34\left[\mathrm{~N} / \mathrm{mm}^{2}\right]$ as the figure shows. On comparing these measured values, one-third of the maximum compressive stress is $11\left[\mathrm{~N} / \mathrm{mm}^{2}\right]$ and the maximum compressive stress $34\left[\mathrm{~N} / \mathrm{mm}^{2}\right]$. We were able to recognize that when (1) arrived, the stress exceeded the allowable value and destruction started and confirmed that the calculated value of the maximum stress at destruction, (3), which coincided well with the measured one. In addition, the voltage output notifying arrival of (2) leading to final destruction was found as shown in the figure.

Figure 6(4) shows results for the English bond specimen and sensor in the glass holder. It is apparent that (1) occurred at around 220 [s] with sensor output of 0.013 [V], (2) occurred at around 380 [s] with sensor output of 0.03 [V], and (3) occurred at around 400 [s] with sensor output of 0.065 [V]. Also,(1) was $15\left[\mathrm{~N} / \mathrm{mm}^{2}\right],(2)$ was $31\left[\mathrm{~N} / \mathrm{mm}^{2}\right]$, and (3) was $33\left[\mathrm{~N} / \mathrm{mm}^{2}\right]$. The calculated value as $1 / 3$ of maximum stress $33\left[\mathrm{~N} / \mathrm{mm}^{2}\right]$ was $11\left[\mathrm{~N} / \mathrm{mm}^{2}\right]$. Although this predicts the start of destruction at around 160 [s], the specimen withstood compressive stress as high as 15 $\left[\mathrm{N} / \mathrm{mm}^{2}\right]$, apparently demonstrating the toughness of English bond. Prediction of destruction was done at $31\left[\mathrm{~N} / \mathrm{mm}^{2}\right],(2)$, against the calculated value of $33\left[\mathrm{~N} / \mathrm{mm}^{2}\right]$ for complete destruction, and (3) coincided with the calculated value.

Summing up these experiment results, the piezoelectric limit sensor generated a warning signal before complete destruction. That warning is not achieved by traditional sensors. The stress of complete destruction was confirmed at the timing calculation anticipated. However, the data notifying the start of destruction scattered slightly. Although we expected the start of destruction to occur at one-third of maximum stress, the actual start of destruction did not occur at this stress to bring about said scattering of data. On the whole, however, we infer that our sensor provided proper signals at the targeted instances.

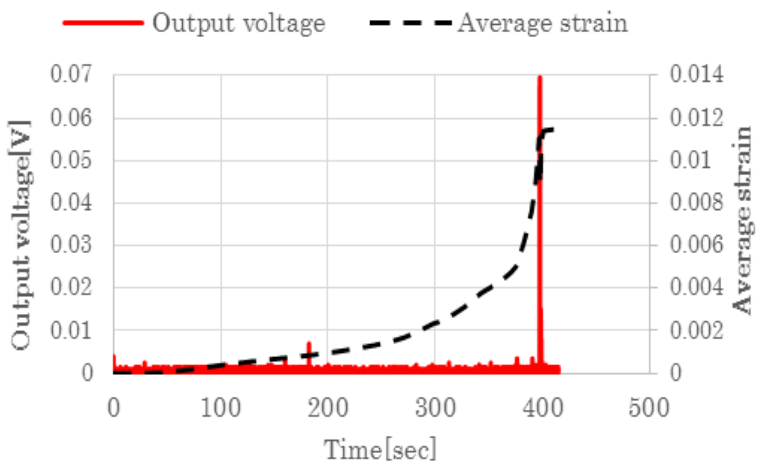

(1) English bond masonry specimen measurement by limit sensor with brass holder for output voltage and average strain. 


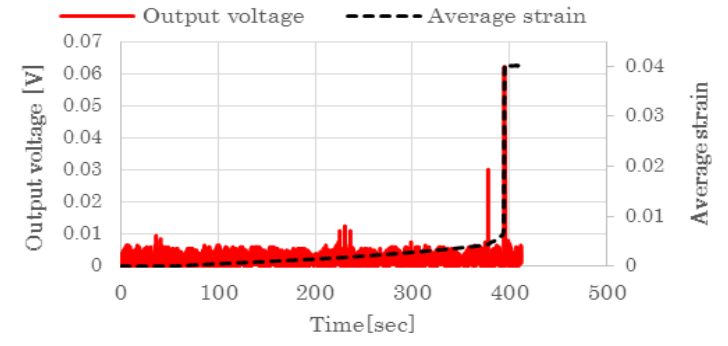

(2) English bond specimen measurement by limit sensor with glass holder for output voltage and average strain.

Fig. 7. Relation piezoelectric limit sensor output and average strain.

Figure 7 shows output of the piezoelectric limit sensor and average strain. Figure 7(1) is for the English bond specimen and sensor in the brass holder. The sensor output is shown as a solid line. (1) occurred at 180 [s], (2) at 380 [s] and (3) at 400 [s], each with typical signal pattern. The strain is shown as a broken line, which indicates the escalation of strain synchronized with sensor output. Warning of destruction by arrival of (2) was done at about $60 \%$ of average maximum compressive stress.

Figure 7(2) is for the English bond specimen and sensor in the glass holder. The sensor output is shown as a solid line. Results show that (1) occurred at through 220-240 [s], (2) occurred at 380 [s], and (3) occurred at 400 [s], each with a typical signal pattern. Strain is shown as a broken line, which shows the escalation of strain concomitantly with the sensor output. Warning of destruction by arrival of (2) occurred rather early at about $10 \%$ of the average maximum compressive stress.

\section{Conclusion}

We proposed a simple monitoring system using a piezoelectric limit sensor for a brick wall of a masonry structure. We examined its performance in comparison with that of traditional system measuring static compressive stress versus strain, obtaining the results presented below.

(1) Our system, using a test method and measurement system with distortion measurement and an accelerometer using a conventional fiber cable, demonstrated measurement of the start of compression destruction in a structure for which prediction was difficult and demonstrated the possibility of measuring stress and distortion when destruction occurs.

(2) A piezoelectric limit sensor inserted into a brick wall of a masonry structure might warn of danger from increasing deformation before complete compressive destruction.

(3) Estimated timings of the maximum compressive stress and the compressive stress at the start of destruction were roughly confirmed by outputs of the piezoelectric limit sensor.

(4) Our simple measuring system, which costs less than one-twentieth of a conventional system using precision vibrometers to measure static loads, provides great convenience and general versatility.

In conclusion, our system incorporating this sensor and analytical devices can detect changes of static loading and abnormal deformation in structures quantitatively. It can function as a health monitoring system for structures. After improving its reliability, our system can be widely used to ensure the strength and safety of brick walls of masonry structures in countries, and particularly in economically developing countries.

\section{Acknowledgements}

This research was partially supported by JSPS KAKENHI Grant Number 25242033, for which we express our appreciation.

\section{References}

[1] N. Shimoi, C. H. Cuadra, H. Madokoro and M. Saijo, Vibration Analysis of Wooden Traditional Frames Using Finite Element Method and Measurements with a Simple Piezoelectric Cable Displacement Sensor, Transactions of Japan Society of Mechanical Engineering, Ser. C, Vol. 79, No. 806, pp. 3442-3452, 2013

[2] N. Shimoi, M. Saijo,C. H. Cuadra, and H. Madokoro, A Study of Measurement for Dangerous Prediction on Static Lording Test Using Piezoelectric Limit Sensors, International Journal of Instrumentation Science.Vol.4,No1.pp1-9,2015

[3] T. Maruyama, The outline of the active fault of the epicentral area of 2008 China Sichuan big earthquake, AFRC NEWS, No. 79, pp. 1-3, 2008

[4] S. Watanabe and M. Samizo, The health monitoring system of bridge pier foundation by measuring slight oscillating movement on a steady basis, Railway Technical Research Institute Report, Vol. 25, No. 7, pp. 25-30, 2011

[5] Structure committee of civil engineering : Subcommittee for design technique of FRP bridge, Report of subcommittee for design technique of FRP bridge, University of Tokyo Press, 2004

[6] K. Ono, A research on life- prolonging technology of established structures, The second new urban socio-technical seminar, Research report 3, Study group to create new urban by fused socio-technology, pp. 11-23, 2004

[7] Building Research Institute, An independent administrative agency, National Institute for Land and Infrastructure Management, Ministry of Land, Infrastructure, Transport and Tourism, About the investigation report on building damage and revival situation after 2008 China Sichuan big earthquake, 2008http://www.nilim.go.jp/lab/bcg/kisya/kako/journal/20081 112.pdf

[8] Tokyo Sensor, Piezoelectric cable, Piezo Film Technical Manual, Vol. R1, pp.17-18, 2001

[9] Liu Ke and S. Shioya, Research on strength testing method of wall of existing brick structures, Collected papers of annual convention of Japan Concrete Institute, Vol. 25, No. 2, pp.1927-1932, 2003

[10] Design of machine elements, Akira Yoshida, Writing and editing, Japanese science and engineering publishing company,pp11-13(2012) 